in water, whether acid, neutral, or alkaline; incoagulability by heat; non-precipitation by acet. plumb. for the most of them. The peptons resulting from either digestion, as a rule, do not contain albumen, at least not more than exists in the normal and pure pancreatic fluid. (10) During the first three hours after food there is no material absorption into the radicles of the portal vein, but yet there occurs a considerable increase in the proportion of albumen contained in the blood. This increase the author ascribes to the agency of the pancreatic juice poured into the duodenum at a time when it is destitute of ingesta; he believes that in the vena porta the globules and the fibrine of the blood are transformed by the absorbed pancreatic secretion into caseiform albumen. (11) No really differential character has been made out between the azotized matters called extractives, and the albuminose produced by gastric or pancreatic digestion. Now, the chyliferous vessels, the vena portce, and its continuation, the hepatic veins-i.e., the vessels which receive most directly the products of digestion, are much richer in extractive matters (albuminose) than the rest of the blood; and so it may be remarked they are in glycose.

Certain pathological inductions may be made from the above conclusions. (A) A duodenal dyspepsia may be induced by the absence, vitiation, or insufficiency of the pancreatic juice. The uneasiness attending this is felt from two to three hours after taking food, and is deeper seated than in gastric dyspepsia. (B) Duodenal dyspepsia may also be induced by any condition which permits unabsorbed or unneutralized gastric juice to mingle with the pancreatic. An excessive amount of gastric secretion, or an open state of the pylorus, or an insufficiency in the biiiary secretion, may all have this effect. (C) The derangement of the intra-venous (portal hepatic) digestion may also occasion a form of dyspepsia.

We have not herewith presented our readers with even a complete summary of our author's views, but we cordially advise them to study the work for themselves. It has the great merit, so commonly possessed by French writers, of being clearly and precisely written; and it has the further recommendation (which the satiated mental appetite will appreciate in these days of book-surfeit) of being short, containing altogether but one hundred and twenty-three pages. We would it had been possible for us to have obeyed the author's injunction, and to have repeated his experiments. Only so could we have really qualified ourselves to criticise accurately his work. But in default of doing this ourselves, we trust that what we have said will induce some of our readers to undertake the duty, and so "sa conviction .... . dans tous Jes cas servira la science, si peu avancée sur ce sujet."

\title{
Art. II.-On Poisons in Relation to Medical Jurisprudence and
} Medicine. By Alfred S. Taylor, M.D., F.R.S., Professor of Medical Jurisprudence and Chemistry in Guy's Hospital, \&c. Second Edition.-London, 1859. pp. 863.

Toxicology, whether we consider it in relation to the science of life, to the detection of crime, or to the chemical art of discovering dele- 
terious substances in organic mixtures, has made immense progress during the eleven years which have elapsed since the appearance of the last edition of this work. The study of the action of poisons on the living organism, which constitutes what may be strictly called the science of toxicology, has been advanced by several extended researches undertaken with a purely scientific object, and without any view to the juridical relations of the questions investigated. In the practical part of the subject a similar progress has been made, and has no doubt been promoted by the occurrence during the last few years of several important criminal trials, which have tended to expose many fallacies, and to establish some valuable principles in medical evidence, and generally to stimulate investigation by drawing public attention to the practical bearing of questions which had before a merely scientific interest.

We are therefore not at all surprised at being told by Dr. Taylor, in his preface, that he has found it impossible within the same limits to treat of all the subjects comprehended in the former edition; and that he has found it necessary to confine himself even more strictly than before to the practical objects of the work. If any one, misled by the title, should take up Dr. Taylor's book, hoping to find in it an exposition of the relations of toxicology to the science of disease, he would be disappointed. In the comparison of the phenomena of disease with those of poisons we have a most valuable means of pathological investigation. On the one hand, we have a poisonous agent capable of being readily isolated, weighed, measured, and experimented on; on the other, the agent is subtle, and for the most part, we know neither whence it cornes nor whither it goes; and even when we have some knowledge of its origin, we cannot seize upon it, or define its nature in any other way than by describing its effects. It is the study of the modus operandi of poisons, as affording the means of making the comparison we have indicated, which constitutes toxicology considered as a branch of the science of medicine; but in this sense, as we have already hinted, it is not included in Dr. Taylor's plan. His book is to be regarded merely as a repertory of all those facts and principles relating to poisons which bear on the detection and proof of crime, its object being to aid the lawyer in the due appreciation of medical testimony, and to fit the medical practitioner for his duties as witness. As a treatise on poisons in relation to crime we think that the work in its present form is the best and most comprehensive in existence in this or in any other language, and that all the modifications which have been introduced into the present edition will be found to be improvements.

As regards the employment of medical men as scientific witnesses, we adhere to the opinion that we expressed ten years ago in our former notice, that it would conduce to the interests of justice, no less than to the credit of the medical profession, that in every case of supposed criminal poisoning the aid of a professed toxicologist should be obtained, and that he should conduct the analysis and be answerable for the whole chemical evidence.

We venture to say that a medical 
man, even if he has made the best possible use of the opportunities of becoming acquainted with practical chemistry commonly afforded by our medical schools, ought not in any ease to take upon himself the responsibility of swearing to the presence or absence of a poison in an organic mixture. We regret that Dr. Taylor has not expressed an opinion on this matter, but we think we may infer that he agrees with us, from the fact that his descriptions of processes of detection are obviously not adapted for the instruction or guidance of the analyst, but rather for the suggestion and solution of all possible objections which might be raised in a court of law to the chemical proof. Dr. Taylor is well aware that no description of the chemical processes required for the detection of a poison, however perspicuous and detailed it may be, will fit a man to undertake an investigation to which he is unaccustomed, and which, even in the hands of those whose life is devoted to similar occupations, is attended with many difficulties.

Among the most important additions are the chapters in which the author has collected the facts relating to the deposition of poisons in the living body, and the period required for their elimination. From these facts it is concluded that the time required for this purpose varies, not only according to the nature of the poison and of the animal observed or experimented on, but that in the same animal or in man the same poison administered under conditions which are apparently similar, may be expelled by the secretions at rates which differ at different times. On this ground Dr. Taylor enforces the necessity of the utmost caution in founding conclusions as to the time which has elapsed since the administration of the poison from the quantity found in the stomach, liver, or other organs. In illustration of the necessity of this caution, Dr. Taylor refers to the well-known trial of Ann Merritt, for the murder of her husband, by the administration of arsenious acid; on this occasion a chemist of note declared upon oath that the poison must, from the quantity found in the stomach of the deceased, have been taken a few hours before death. This opinion was purely speculative, for although arsenic is absorbed and eliminated more rapidly than any other metallic poison, excepting antimony, there are no facts to prove that it would disappear from the stomach in so short a time as a few hours, or even a day. At the trial of William Palmer, an opinion was expressed by Dr. Taylor himself, which at first sight appears similar: but here the question was one not of hours, but of weeks. It was then said that the presence of antimony in the contents of the stomach and intestines indicated that it had been administered within three weeks of death. This inference the author shows, we think satisfactorily, not only to be in accordance with all that was then known on the subject, but to be further supported by the experiments of Dr. Nevin, of Liverpool, undertaken since the trial, with a special view to the elucidation of the question.

We regret that our space does not allow us to pass on to the other chapters which distinguish this edition from the last. We invite the 
attention of the reader especially to those which treat of poisoning by opium and nux vomica and their respective alkaloids. . With regard to these, the opinion is maintained that no single chemical reaction should be admitted as proof of their presence; and that the value of any process used for detecting them is to be estimated, not so much by its delicacy, as by the absolute certainty of the results which it is capable of yielding.

Art. III.-Sulle Virtŭ Igieniche e Medicinali della Coca, e sugli Alimenti Nervosi in Generale. Del Dottor Mantegazza.-Milano, 1859. pp. 76.

On the Hygienic and Medicinal Virtues of Coca, and Tonic Articles of Diet generally. By Dr. Mantegazza.

THE author accepts the distinctions which Liebig has drawn between the plastic or nitrogenous, and the respiratory or carbonaceous articles of food. To these two he proposes to add a third class, the "alimenti nervosi," which have a stimulating effect upon the nervous system. $\mathrm{He}$ gives a classification of the various articles belonging to this class, of which he makes three subdivisions-the alcoholic, the alkaloid, and the aromatic. The substances comprised in the second of these subdivisions owe their properties to a peculiar alkaloid, and are farther subdivided into the coffee-like substances, such as tea, coffee, chocolate, and Paraguay tea; and the narcotic, such as opium, Indian hemp, and coca.

Coca is the dried leaves of a shrub which grows extensively in Bolivia, and on the Andes of Peru. It is the Erythroxylon coca of Lamarck, and belongs to the natural order Erythroxylaceæ. Some idea may be formed of the immense extent to which the substance is employed, from the fact that the value of the amount annually produced in the republic of Bolivia is estimated at twelve millions of francs. Its use appears to be limited to Bolivia, Peru, and certain provinces of the Argentine Confederation, and consists in slow mastication along with certain other substances.

Its physiological actions are said to be the following:

1. It stimulates the stomach and promotes digestion.

2. In large doses it augments animal heat, and accelerates the pulse and respiration.

3. It induces slight constipation.

4. In moderate doses (1-4 drachms) it stimulates the nervous system, so as to render it more tolerant of muscular fatigue.

5 . In larger doses it gives rise to hallucinations and true delirium.

6. Its most precious property is that of inducing the most pleasant visions ("fantasmagoria") without any subsequent depression of the nervous energies.

7. Probably it diminishes some of the secretions.

The author observes that the antipathy against coca, which the vicious practice of chewing it, prevalent among the inhabitants of Bolivia 